\title{
The Phytophthora infestans Avirulence Gene Avr4 Encodes an RXLR-dEER Effector
}

\author{
Pieter M. J. A. van Poppel, ${ }^{1,2}$ Jun Guo, ${ }^{1,3}$ Peter J. I. van de Vondervoort, ${ }^{1}$ Maartje W. M. Jung, ${ }^{1}$ \\ Paul R. J. Birch, ${ }^{4}$ Stephen C. Whisson, ${ }^{4}$ and Francine Govers ${ }^{1,2}$ \\ ${ }^{1}$ Laboratory of Phytopathology, Wageningen University, Binnenhaven 5, 6709 PD Wageningen and Graduate School \\ Experimental Plant Sciences, The Netherlands; ${ }^{2}$ Centre for BioSystems Genomics (CBSG), P.O. Box 986700 AB \\ Wageningen, The Netherlands; ${ }^{3}$ Institute of Vegetables and Flowers, Chinese Academy of Agricultural Sciences, Beijing \\ 100081 and College of Plant Protection, Northwest A \& F University, Yangling Shaanxi 712100, China; ${ }^{4}$ Plant-Pathology \\ Programme, Scottish Crop Research Institute, Invergowrie, Dundee DD2 5DA, Scotland, U.K.
}

Submitted 14 March 2008. Accepted 30 June 2008.

\begin{abstract}
Resistance in potato against the oomycete Phytophthora infestans is conditioned by resistance $(R)$ genes that are introgressed from wild Solanum spp. into cultivated potato. According to the gene-for-gene model, proteins encoded by $\boldsymbol{R}$ genes recognize race-specific effectors resulting in a hypersensitive response (HR). We isolated $P$. infestans avirulence gene PiAvr4 using a combined approach of genetic mapping, transcriptional profiling, and bacterial artificial chromosome marker landing. PiAvr4 encodes a 287-amino-acidprotein that belongs to a superfamily of effectors sharing the putative host-cell-targeting motif RXLR-dEER. Transformation of $P$. infestans race 4 strains with PiAvr4 resulted in transformants that were avirulent on $R 4$ potato plants, demonstrating that PiAvr4 is responsible for eliciting $\mathbf{R} 4$ mediated resistance. Moreover, expression of PiAvr4 in R4 plants using PVX agroinfection and agroinfiltration showed that PiAvr4 itself is the effector that elicits HR on $R 4$ but not $r 0$ plants. The presence of the RXLR-dEER motif suggested intracellular recognition of PiAvr4. This was confirmed in agroinfiltration assays but not with PVX agroinfection. Because there was always recognition of PiAvr4 retaining the signal peptide, extracellular recognition cannot be excluded. Deletion of the RXLR-dEER domain neither stimulated nor prevented elicitor activity of PiAvr4. Race 4 strains have frame shift mutations in PiAvr4 that result in truncated peptides; hence, PiAvr4 is apparently not crucial for virulence.
\end{abstract}

Additional keywords: late blight, plant pathogen, RXLR motif.

Pieter M. J. A. van Poppel and Jun Guo contributed equally to this article.

Corresponding author: F. Govers; Telephone: (+31) 317483 138; Fax. (+31) 317483 412; E-mail: Francine.Govers@wur.nl

Current address of P. J. I. van de Vondervoort: DSM Food Specialties, PO Box 1, 2600 MA Delft, The Netherlands.

Current address of P. M. J. A. van Poppel: De Ruiter Seeds R\&D NL B.V., PO Box 1050, 2660 BB Bergschenhoek, The Netherlands.

Sequence data have been submitted to GenBank under accession numbers EF672354 and EF672355.

* The $\boldsymbol{e}$-Xtra logo stands for "electronic extra" and indicates that four supplemental tables and three supplemental figures are published online. Figure 3 also appears in color online.
Plants are attacked by a variety of pathogens and have, as a countermeasure, developed defense mechanisms that result in innate immunity (Chisholm et al. 2006; Jones and Takemoto 2004; Nürnberger et al. 2004). In most cases, pathogen attack is unsuccessful; the plant will not host the pathogen (a nonhost interaction) and the pathogen is unable to overcome the defense barriers. However, when the pathogen encounters a suitable host, it is able to overcome or suppress the defense barriers and can successfully invade and colonize the plant tissues. The most devastating pathogen on potato (Solanum tuberosum) is Phytophthora infestans, the oomycete that causes late blight and was responsible for the Irish potato famine in the 1840s (Govers and Latijnhouwers 2004). To combat this disease, breeders have introduced resistance $(R)$ genes from wild Solanum spp. into cultivated potato. Proteins encoded by these $R$ genes can recognize specific races of the pathogen. This triggers defense responses often leading to a hypersensitive response (HR) that arrests growth of the pathogen. Potato and $P$. infestans interact according to the gene-for-gene model (Flor 1971), which predicts that recognition is governed by direct or indirect interaction of an $\mathrm{R}$ protein with its corresponding effector, the product of an avirulence $(A v r)$ gene. If either the $R$ gene or the $A v r$ gene is absent or nonfunctional, the interaction is compatible and the host susceptible. This model also predicts that the durability of an $R$ gene is highly dependent on the stability or role of its cognate effector. That is, if an Avr gene can easily mutate without fitness penalty, the pathogen can circumvent recognition and resistance is overcome.

$P$. infestans is notorious for its adaptive ability in response to $R$ genes (Wastie 1991). The first attempts to breed lateblight-resistant potato plants were disappointing. The $11 R$ genes that were introgressed in potato from $S$. demissum (Black et al. 1953; Malcolmson and Black 1966; Mastenbroek 1953) were all defeated within 5 years and breeders lost confidence in this approach. Lately, interest in $R$ gene breeding has revived and two $R$ genes from durable resistant $S$. bulbocastanum accessions were cloned (Song et al. 2003; van der Vossen et al. 2003, 2005). Key to a better understanding of the molecular basis of late blight resistance is dissecting $\mathrm{R}$ protein-effector interactions and, thus, there is a need to have more cloned $R$ and $A v r$ genes available to study these interactions. In addition to the two $S$. bulbocastanum $R$ genes, named Rpi-blb1 and Rpi-blb2 (Song et al. 2003; van der Vossen et al. 2003, 2005), a few other late blight $R$ genes have been cloned, including two from $S$. demissum, $R 1$ (Ballvora et al. 2002) and $R 3 a$ (Huang et al. 2005). They all 
encode nucleotide binding site leucine-rich repeat (NBSLRR)-type $\mathrm{R}$ proteins that are predicted to reside in the cytoplasm. So far, only for $R 3 a$ has the corresponding $A v r$ gene been isolated. Avr $3 a$ was identified by association genetics and, with the help of the cloned $R 3 a$ gene, its avirulence function was demonstrated (Armstrong et al. 2005). Avr3a belongs to a large, oomycete-specific family of highly divergent effectors that share a conserved domain named RXLRdEER (Rehmany et al. 2005; Tyler et al. 2006). Recent analyses have suggested that the RXLR-dEER genes in $P$. ramorum and $P$. sojae are derived from a common ancestor (Jiang et al. 2008). The RXLR motif is also present in effectors encoded by $A v r 1 b-1$ from $P$. sojae (Shan et al. 2004), and $A T R 1^{N d W s B}$ (Rehmany et al. 2005) and ATR13 (Allen et al. 2004) from the Arabidopsis downy mildew pathogen Hyaloperonospora parasitica. These latter three were obtained by map-based cloning and, similar to the late blight $R$ genes, the $R$ genes recognizing $A T R 1^{N d W s B}$ and $A T R 13$ (i.e., $R P P 1$ and $R P P 13$, respectively) encode NBS-LRR proteins (Catanzariti et al. 2007). As yet, conserved domains have not been found in any of the fungal or bacterial Avr effectors that interact with NBS-LRR-type R proteins (Birch et al. 2006; Catanzariti et al. 2007; Kjemtrup et al. 2000). Therefore, it is remarkable that nearly all oomycete $A v r$ loci that were cloned by unbiased approaches encode effector genes belonging to the RXLRdEER family. The one exception is the Avr3b-Avr10-Avr11 locus in P. infestans. This locus harbors the Pi3.4 gene that encodes a putative regulatory protein (Jiang et al. 2006).

In order to isolate $P$. infestans Avr genes, we initially followed a map-based cloning approach and positioned several $A v r$ genes on high-density genetic linkage maps (van der Lee et al. 2001). A $P$. infestans bacterial artificial chromosome (BAC) library was made from a progeny predicted to contain all six Avr alleles segregating in this population (Whisson et al. 2001). Because the map resolution was insufficient for chromosome walking, additional markers were obtained using expression profiling. To identify Avr-associated transcripts, transcriptional profiling using cDNA-amplified fragment length polymorphism (AFLP) was performed on pools of F1 progeny segregating for avirulence. Avr genes are expected to be expressed prior to penetration of the host and, therefore, RNA from germinated cysts was used as cDNA-AFLP template (Guo et al. 2006). Here, we describe cloning and functional characterization of the $P$. infestans Avr4 gene, the counterpart of the late blight resistance locus from $S$. demissum that is denoted as $R 4$ (Black et al. 1953; Mastenbroek 1953). Previously, the Avr4 locus was positioned on linkage group A2-a with nine AFLP markers in close vicinity (van der Lee et al. 2001). Added to that were two cDNA-AFLP markers that were specific for strains avirulent on $R 4$ plants. In this study, the AFLP and cDNA-AFLP markers were used for BAC landing and a gene located at the Avr4 locus was identified. PiAvr4 encodes a typical oomycete RXLR effector molecule, elicits an HR when expressed in $R 4$ potato plants, and can complement the avr4 phenotype in race 4 strains. Taken together, these results show that recognition of PiAvr4 underlies R4-mediated resistance in potato.

\section{RESULTS}

Two cDNA-AFLP fragments cosegregate with the Avr4 locus and are derived from the same gene.

Using cDNA-AFLP, we previously identified 23 Avr4-associated transcript-derived fragments (TDF). Two of these, TDF4.1s and TDF4.2s, showed $100 \%$ association with the AVR4 phenotype in $18 \mathrm{~F} 1$ progeny of a mapping population (cross 71) (Guo et al. 2006). BLASTN screening of an expressed sequence tag (EST) database (Randall et al. 2005) with the TDF4.1s and TDF4.2s sequences resulted in a match of both TDF to PH051G10, an EST of 748 nucleotides and no homology to known genes.

To confirm that expression of the gene corresponding to PH051G10 is associated with the AVR4 phenotype, we performed reverse-transcriptase polymerase chain reaction (RTPCR) expression analysis with primers specific for PH051G10. Transcripts were found in germinated cysts of all tested avirulent progeny of cross 71 and parental isolate NL88133 but not in virulent progeny or parental isolate NL80029. Occasionally, a faint band was observed in a virulent F1 strain (e.g., D12-27) but the transcript level was always much lower than in avirulent strains (Fig. 1) (data not shown). This shows that, in the mapping population, expression in germinated cysts of a gene represented by TDF4.1s, TDF4.2s, and EST PH051G10 cosegregates with the Avr4 locus.

\section{Avr4-linked AFLP markers and a candidate Avr4 gene are located on a single BAC contig.}

Previously, we used a mapping population of $76 \mathrm{~F} 1$ progeny (cross 71) to position the Avr4 locus on linkage group A2-a and identified nine AFLP markers closely linked to Avr4 (van der Lee et al. 2001). Five of these were used to screen a $10 \times$ coverage BAC library of strain T30-4, an F1 progeny of cross 71 that is avirulent on $R 4$ plants. This gave nine positive BACs that could be assembled in one contig (Fig. 2A) (Supplementary Table S1). Subsequently, these BACs were screened by PCR with primers derived from EST PH051G10. Seven of the nine were positive and this was confirmed by Southern hybridization with TDF4.1s and TDF4.2s probes. This demonstrated that the candidate Avr4 gene and the AFLP markers genetically linked to Avr4 are located on this BAC contig.

\section{PiAvr4 encodes an RXLR-dEER protein.}

From three overlapping BACs (BAC01E13, BAC38B05, and BAC40K10), we subcloned a 2.9-kb BamHI fragment that hybridized to both TDF4.1s and TDF4.2s. Sequencing revealed a single 861-bp open reading frame (ORF) encoding a 287 amino-acid (aa) protein with a predicted 24-aa signal peptide (SP) (Fig. 2B). Overall, the protein showed no homology to any known protein but contained a conserved motif that had been identified in several oomycete Avr factors encoded by genes interacting in a gene-for-gene manner with $R$ genes (Rehmany et al. 2005). Manual alignment showed that the relative position of the conserved RXLR-dEER motif with respect to the SP is comparable. Our candidate Avr4 protein also

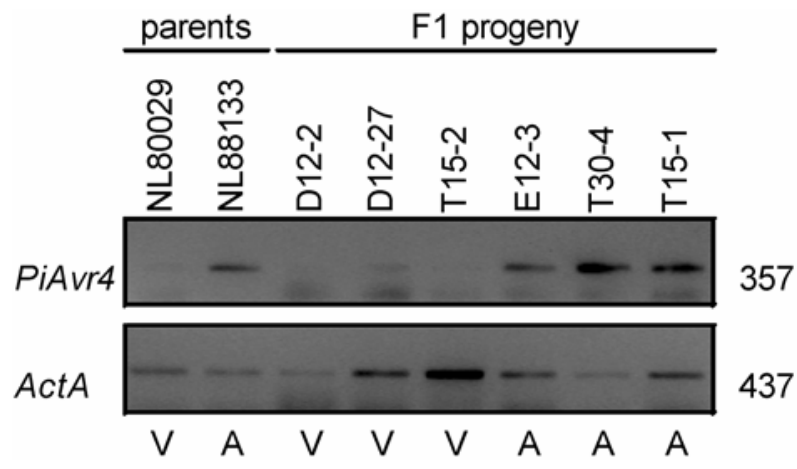

Fig. 1. Expression of a putative PiAvr4 gene in the parental isolates NL80029 and NL88133, and seven F1 progeny. Reverse-transcriptase polymerase chain reaction products obtained with primers specific for PH051G10 (upper panel) and the actin A gene ActA (lower panel), and total RNA isolated from germinated cysts as template. Amplicon sizes (right) are in base pairs. A and $\mathrm{V}$ refer to the avirulent or virulent phenotype, respectively, on $R 4$ plants. 
followed that pattern (Fig. 2C) and we tentatively named the gene PiAvr4. In the PiAvr4 protein, the conserved motif starts with RFLR at amino acid position 18 of the mature protein and ends at position 31 with a dEER region lacking the aspartic acid residue (D).

\section{The 'virulent' allele}

at the Avr4 locus encodes a truncated protein.

Strain T30-4 is heterozygous at the Avr4 locus. To identify the virulent allele of PiAvr4, we hybridized the BAC library with a $3^{\prime}$ untranslated region (UTR) probe. Sixteen Avr4-positive BACs were identified, nine of which were not selected in the screening with Avr4-linked AFLP markers. PCR, Southern hybridization, restriction analysis, and sequencing revealed that six of the nine carry an allelic variant that is located on a 3.8-kb SalI fragment, while three BACs fit in the contig and carry PiAvr4 (Fig. 2). Compared with PiAvr4, the allelic variant (i.e. Piavr4) has 15 single-nucleotide polymorphisms (SNP) and two single-base-pair deletions $\left(\Delta \mathrm{T}^{12}\right.$ and $\left.\Delta \mathrm{T}^{196}\right)$ (Supplementary Fig. S1). The two deletions cause frame-shift mutations and premature stop codons, resulting in a truncated protein of only 17 aa that probably is not functional.

The promoter regions in the two alleles are similar up to approximately 500 bp upstream of the start codon but, further upstream, the sequences diverge dramatically. Between -500 and +1 there are five SNP and nine indels ranging from 1 to 10 bp. In the promoter, the 16-nucleotide oomycete core consensus sequence that surrounds the putative transcription start site (TSS) is located between -38 and -23 relative to the ATG start codon (McLeod et al. 2004; Pieterse et al. 1994). Apart from a 1-bp indel at the $3^{\prime}$ end, the core consensus TSS sequence is identical in the two alleles. Downstream of the stop codon of
PiAvr4, 107 bp of the 3' UTR were compared with the equivalent portion of the Piavr4 allele and only one SNP was found.

\section{Complementation of race 4 strains with PiAvr4 results in a change in phenotype.}

To determine whether PiAvr4 is the avr gene interacting with the $R 4$ gene, we transformed race 4 strains with a plasmid carrying PiAvr4 under control of its native promoter and monitored the ability of the transformants to infect $R 4$ plants. Plasmid pTA23.9 contains a 2.9-kb BamHI fragment from BAC01E13, and harbors the PiAvr4 ORF with 1,454 bp upstream of the ATG and 572 bp downstream of the stop codon. As recipient strains, we used T35-3 and D12-2, two F1 progeny of cross 71 and siblings of T30-4. Four transformants showed a change in phenotype: TA2.3, DA4.2, TA5.4, and TA5.5 were still pathogenic on Bintje, a susceptible cultivar lacking $R$ genes $(r O)$, but were no longer able to infect $R 4$ plants (Fig. 3; Table 1 ). Inoculation on two different $R 4$ plants, the breeding line Cebeco4431-5 and cv. Isola, resulted in an HR whereas inoculation with the recipient strains resulted in sporulating lesions. With each of the transformants, the infection assays were repeated at least three times and the avirulent phenotypes on $R 4$ plants were always confirmed. In all cases, the transformants could easily infect and colonize Bintje but the lesion growth rate was slightly reduced when compared with the wild-type recipient strains (Table 1). To confirm expression of the transgene, we performed RT-PCR expression analysis and showed the presence of PiAvr4 transcripts in germinated cysts of the transformants. These transcripts were not detected in the nontransformed recipient strains T35-3 and D12-2 (Table 1). Altogether, these results demonstrate that PiAvr4 conditions avirulence of $P$. infestans on potato plants carrying $R 4$.

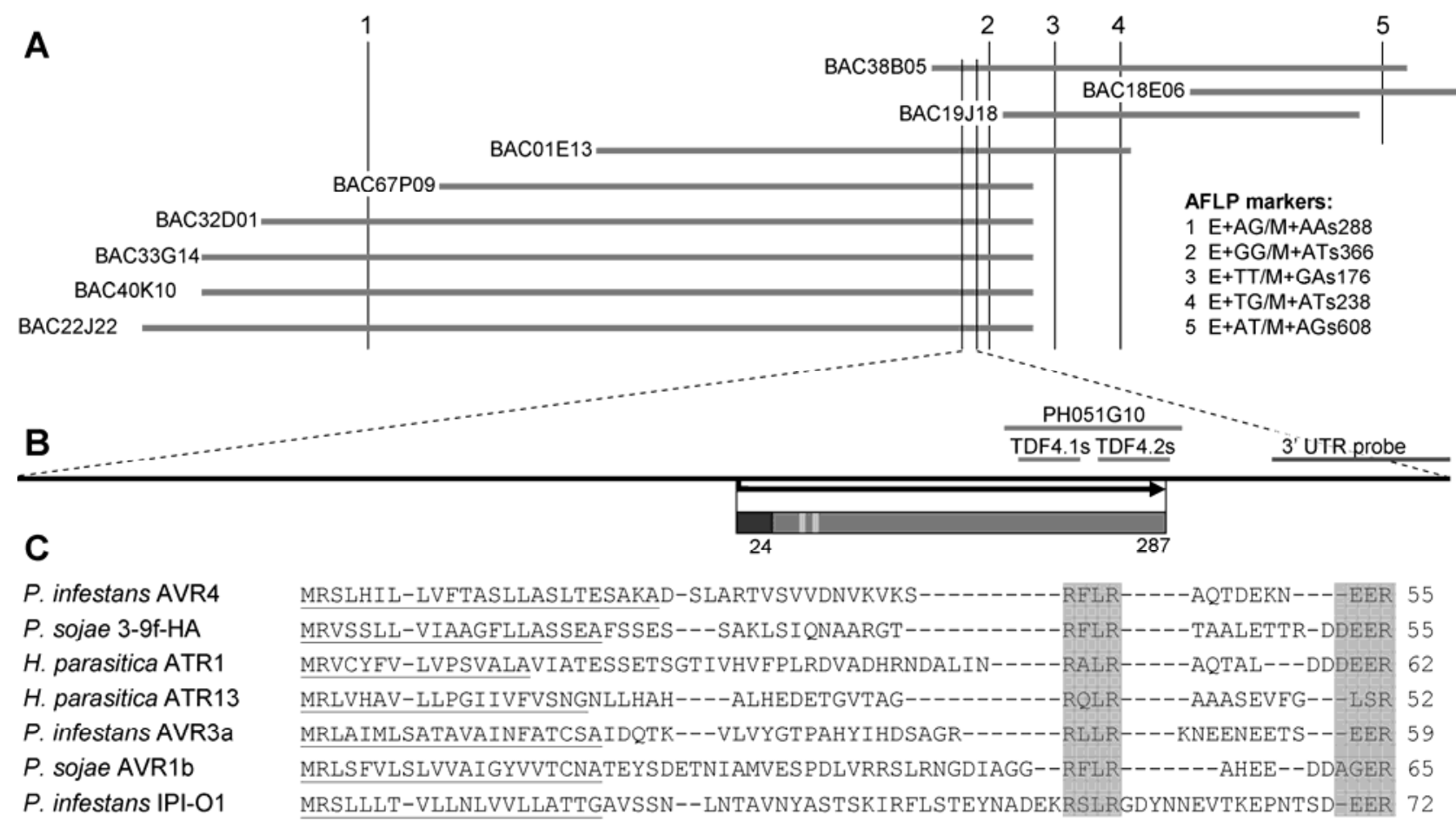

Fig. 2. A, Bacterial artificial chromosome (BAC) contig spanning the Avr4 locus. The nine BACs were selected by screening the BAC library with Avr4linked amplified fragment length polymorphism markers, indicated by 1 to 5 . The sizes of the BACs are estimated and not drawn on scale. B, The 2,890-bp BamHI fragment carrying PiAvr4. The open reading frame of $861 \mathrm{bp}$ (black arrow) starts at base pair position 1,455. The black line represents the 3' untranslated region probe (a 465-bp SalI-BamHI fragment). The bar represents PiAvr4 with the predicted signal peptide (SP) of 24 amino acids (black box) and the RXLR and dEER motifs (light gray). C, Alignment of the N-terminal portion of oomycete effector proteins. Shown are Phytophthora infestans PiAvr4, P. sojae 3-9f-HA (accession AY183415), Hyaloperonospora parasitica ATR1 (AY842877), H. parasitica ATR13 (AY785306), P. infestans AVR3a (AJ893357), P. sojae AVR1b (AY426744), and P. infestans IPI-O1 (L23939). Sequences were manually aligned. The RXLR-dEER motif is highlighted and the predicted SPs are underlined. 


\section{Expression of PiAvr4 in $\boldsymbol{R} 4$ plants results in an HR.}

To investigate if PiAvr4 itself has elicitor activity, we expressed PiAvr4 in planta by means of agroinfection and compared the responses in different solanaceous plants. The ORF of PiAvr4 was cloned in the binary PVX vector pGR106 and transformed into Agrobacterium tumefaciens GV3101. Toothpick inoculation of $A$. tumefaciens carrying pGR106-Avr4 ${ }^{1-287}$ resulted in an HR on $R 4$ plants within 13 days postinoculation (dpi) whereas Bintje $(r O)$ and the $R 3 a$ potato breeding line SW8540-025 showed no response (Fig. 4A). Also, on Nicotiana tabacum and $N$. clevelandii, nonhost species that show no macroscopic responses upon drop inoculation with $P$. infestans zoospores, there was no visible response. As positive control, we used pGR106-CRN2. CRN2, which is a general necrosis induc- ing elicitor (Torto et al. 2003), elicited responses on $N$. tabacum and $N$. clevelandii as well as on all tested potato lines, including $R 4$ plants and Bintje (Fig. 4A). Inoculation with strains carrying the empty vector pGR106 gave no response. These results show that PiAvr4 is an elicitor of HR on plants carrying R4.

Because PiAvr4 has an RXLR-dEER motif that may function as a host targeting signal (HTS) (Whisson et al. 2007), we anticipated that, in the agroinfection assays, the SP would not be required for HR-inducing activity. To test this, we constructed plasmid pGR106-Avr4 $4^{25-287}$ that lacks the sequence for the SP. Surprisingly, none of the $R 4$ plants responded with a visibly detectable $\mathrm{HR}$ to agroinfection with strains carrying pGR106-Avr4 ${ }^{25-287}$ (Fig. 4A), and neither did any of the control lines tested. Two independent pGR106-Avr $4^{25-287}$ constructs, of

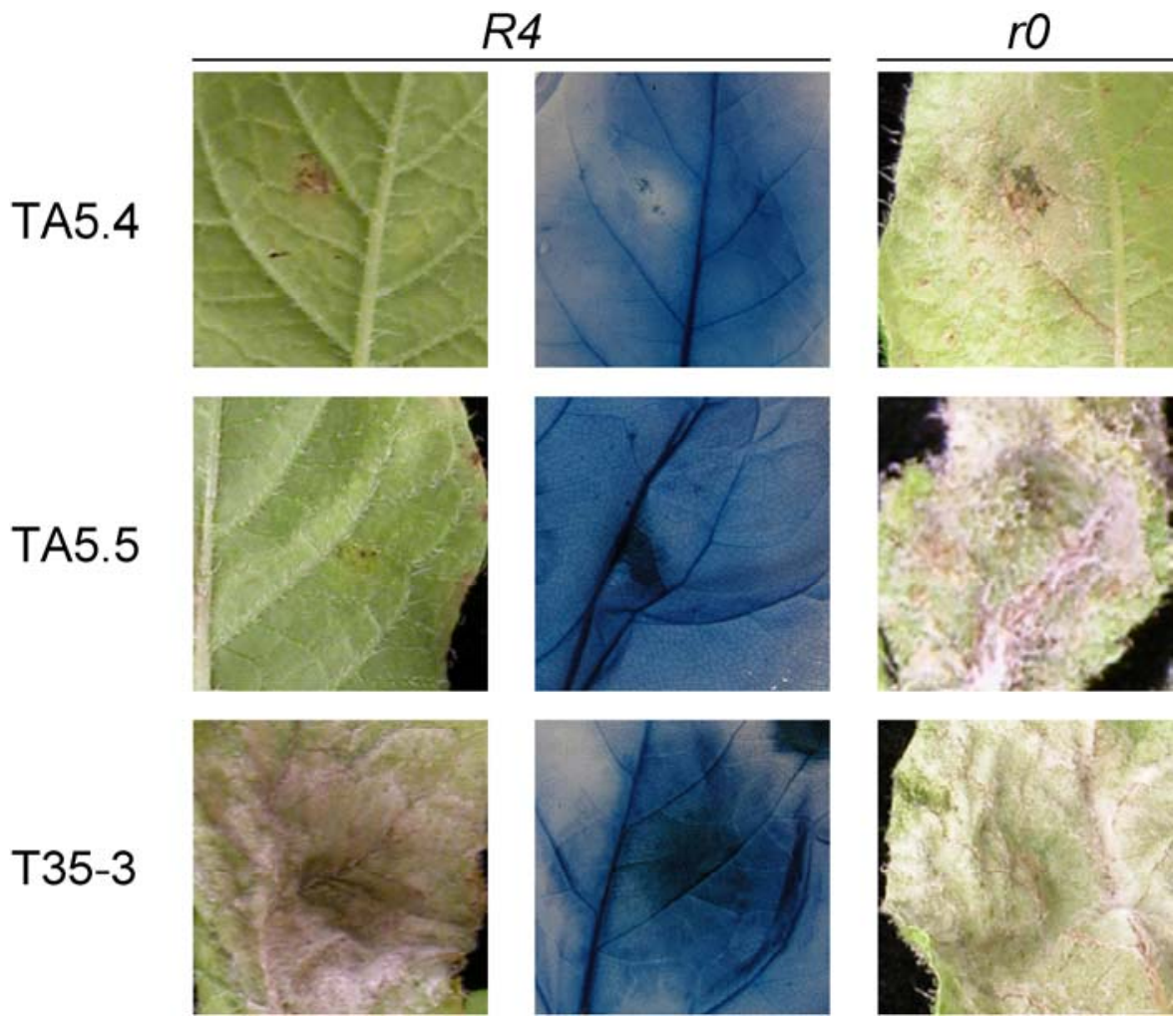

Fig. 3. Virulence phenotypes of recipient strain T35-3 and transformants complemented with PiAvr4 (TA5.4 and TA5.5) on leaves of potato cvs. Bintje (rO) and Cebeco44-31-5 (R4). The middle column shows the $R 4$ leaves displayed in the left column after trypan blue staining. Leaves were spot-inoculated with equal numbers of zoospores. Photographs were taken 5 days postinoculation.

Table 1. Infection efficiency (IE) and lesion growth rate (LGR) of Phytophthora infestans donor and recipient strains (F1 progeny), PiAvr4 transformants, and field isolates on cvs. Bintje $(r O)$ and Isola $(R 4)^{\mathrm{a}}$

\begin{tabular}{|c|c|c|c|c|c|c|}
\hline \multirow[b]{2}{*}{ Strain } & \multirow[b]{2}{*}{ Origin } & \multirow[b]{2}{*}{ PiAvr4 mRNA ${ }^{\mathrm{b}}$} & \multicolumn{2}{|c|}{ Bintje $(r 0)$} & \multicolumn{2}{|c|}{ Isola $(R 4)$} \\
\hline & & & IE & LGR & IE & LGR \\
\hline T30-4 & Progeny of cross 71 & + & 100 & 0.79 & 25 & 0.14 \\
\hline D12-2 & Progeny of cross 71 & - & 100 & 0.73 & 75 & 0.51 \\
\hline T35-3 & Progeny of cross 71 & - & 100 & 0.83 & 100 & 0.53 \\
\hline DA4.2 & D12-2 transformant & + & 100 & 0.55 & 17 & 0.15 \\
\hline TA2.3 & T35-3 transformant & + & 100 & 0.28 & 17 & 0.15 \\
\hline TA5.4 & T35-3 transformant & + & 100 & 0.42 & 0 & 0 \\
\hline TA5.5 & T35-3 transformant & + & 100 & 1.15 & 0 & 0 \\
\hline NL80029 & Field isolate; A1 parent of cross 71 & - & 75 & 0.6 & 100 & 0.5 \\
\hline NL88133 & Field isolate; A2 parent of cross 71 & + & 100 & 0.8 & 0 & 0 \\
\hline $\mathrm{NL}_{88069^{\mathrm{c}}}$ & Field isolate & + & 100 & 0.9 & 100 & 0.46 \\
\hline IPO-0 ${ }^{\mathrm{d}}$ & Field isolate & + & 100 & 0.94 & 0 & 0 \\
\hline
\end{tabular}

${ }^{a}$ IE is expressed as the percentage of successful infections per plant genotype and LGR of successful infections is expressed in centimeters per day. LGR was determined by comparing the infected area on day 3 and day 5 in a single experiment using six independent inoculations per tested isolate.

${ }^{\mathrm{b}}$ Transcripts were detected by reverse-transcriptase polymerase chain reaction on mRNA isolated from germinated cysts using primers matching PiAvr4.

${ }^{\mathrm{c}}$ In NL88069, only allele XIII has been identified; this allele has a frame-shift mutation resulting in a truncated protein.

${ }^{\mathrm{d}}$ IPO-0 contains virulent allele $\mathrm{V}$ and avirulent allele II (Fig. 6). 
A

pGR106

pGR106-Avr41-287
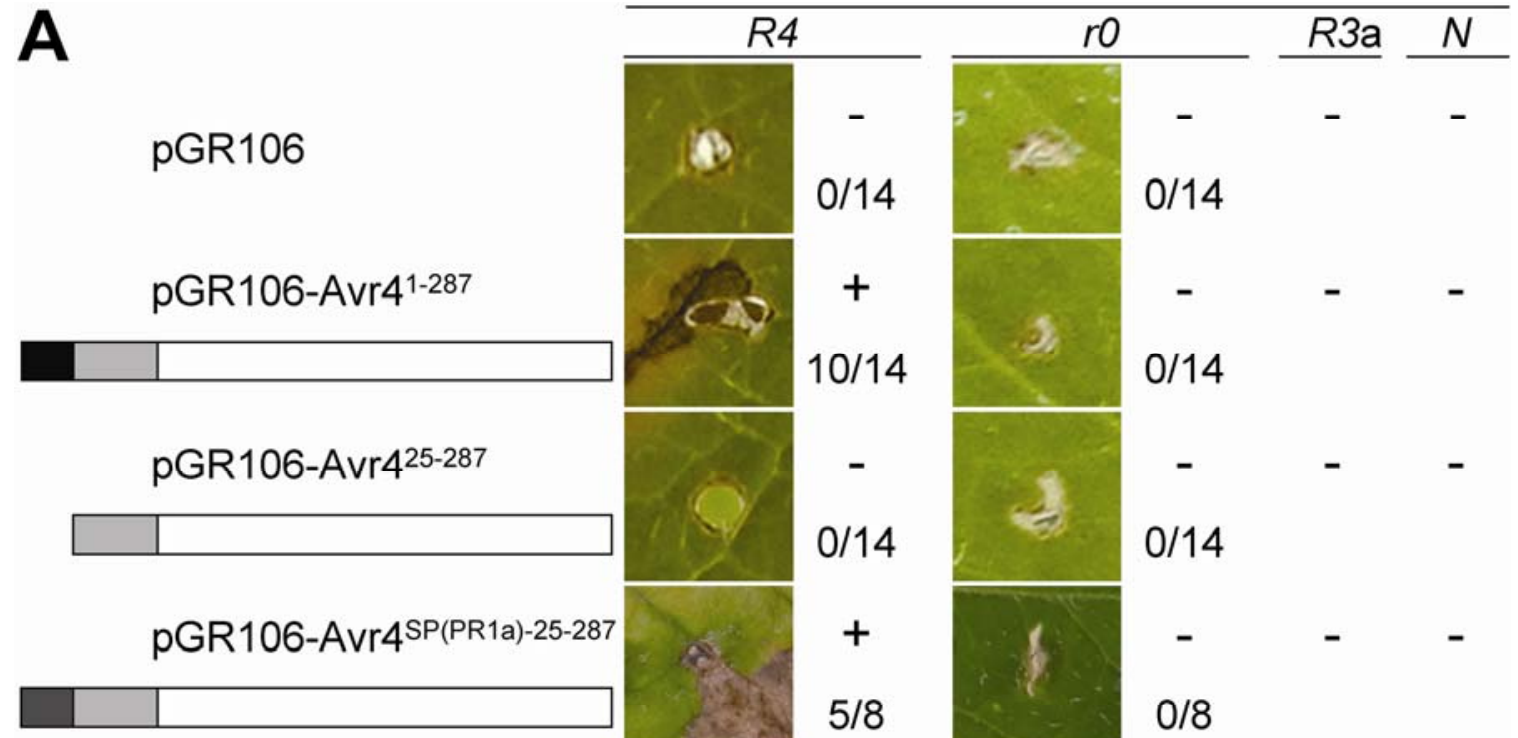

$+$

$10 / 14$
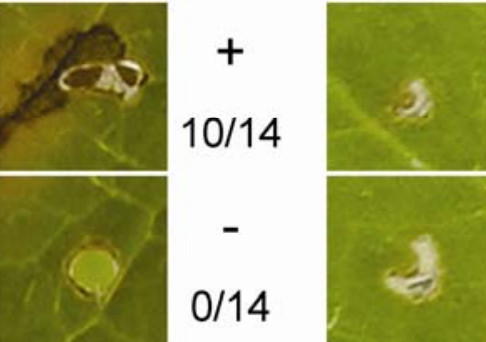

-

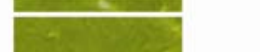

$0 / 14$

$0 / 14$

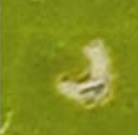

$0 / 14$

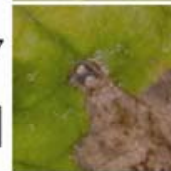

$+$

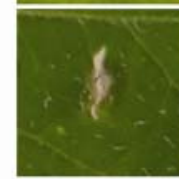

-

$5 / 8$

$0 / 8$

pGR106-Avr4SP(PR1a)-66-287

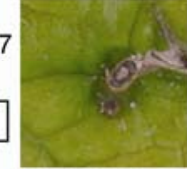

$+$

$5 / 8$

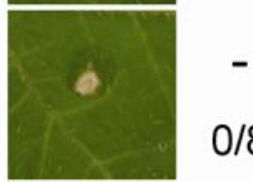

pGR106-Avr466-287
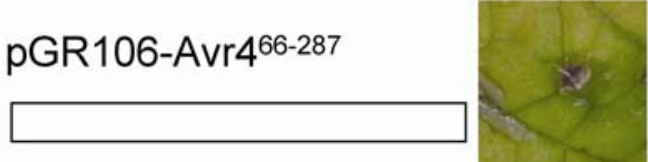

-

pGR106-CRN2

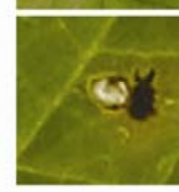

\section{$0 / 8$}
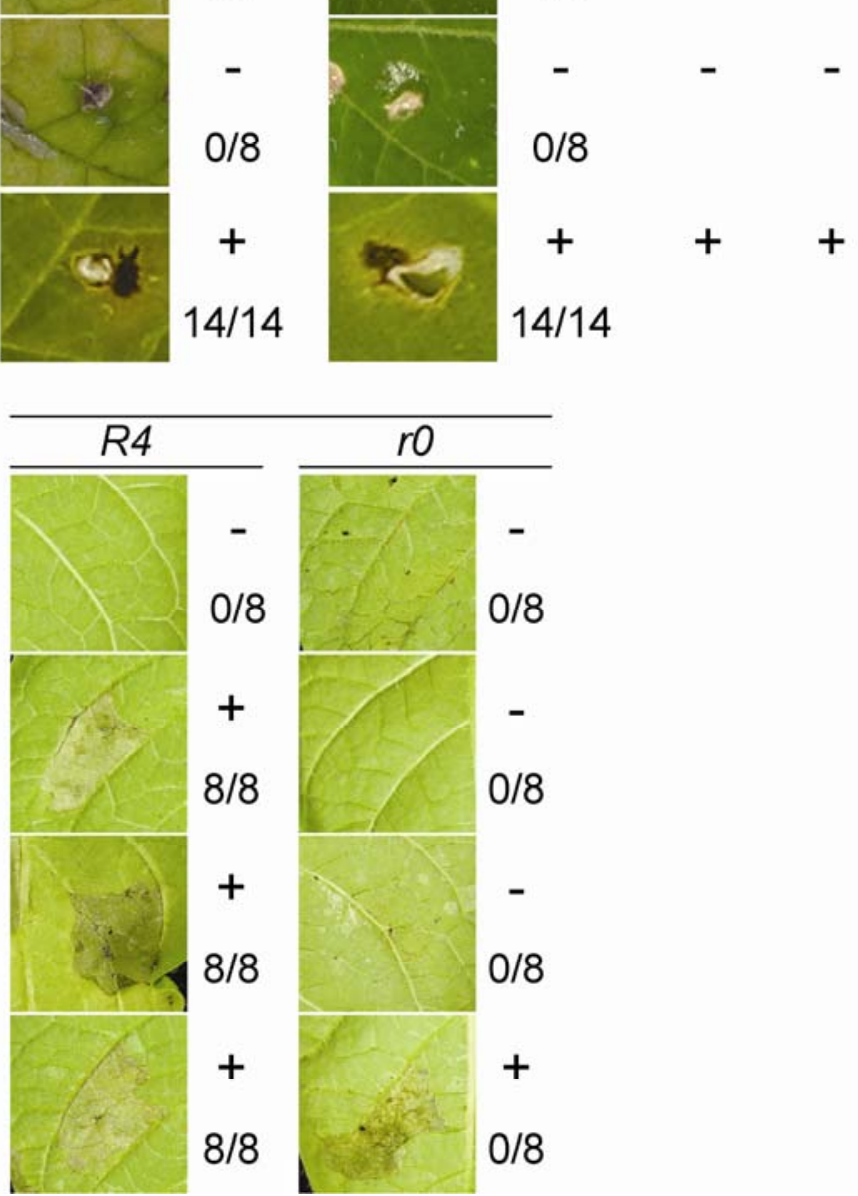

Fig. 4. A, Expression of PiAvr4 in plants. A, Agroinfection and B, agroinfiltration of potato line Cebeco44-31-5 ( $R 4$ ) and cultivar Bintje ( $r 0)$ by toothpick inoculation with strains carrying pGR106 constructs (in A) and with Agrobacterium tumefaciens strains carrying pGRAB constructs (in B). + indicates a necrotic response and - indicates no visual response. The numbers show the ratio of '+' responses and total number of toothpick inoculations (in A) or the ratio of ' + ' responses and total number of agroinfiltrations (in B) in a typical experiment. Pictures were taken 18 days postinoculation (dpi) (in A) or 3 dpi (in B). Controls for agroinfection included inoculations on potato line SW8540-025 (R3a) and two Nicotiana species, N. tabacum and N. clevelandii (N), which responded similarly. In the schematic representation of the constructs, the signal peptide (SP) of PiAvr4 is shown in black, the SP of PR1a in dark gray, the RXLR-dEER region (aa 25 to 65) in light gray, and the C-terminal region (aa 66 to 287) as an open bar. CRN2, cloned in pGR106-CRN2 and pGRABCRN2, is a universal elicitor that is used as positive control. 
which the identity was confirmed by DNA sequencing, gave comparable results. To exclude the possibility that the native SP of PiAvr4 in pGR106-Avr4 ${ }^{1-287}$ does not function properly in plants, we replaced it with the tobacco PR1a SP. Agroinfection with strains carrying pGR106-Avr4 ${ }^{\text {SP(PR1a)-25-287 }}$ gave the same result as the strains carrying pGR106-Avr4 $4^{1-287}$ (i.e., an $\mathrm{HR}$ on $R 4$ plants and no response on Bintje or $N$. clevelandii) (Fig. 4A).

The absence of any visible response with constructs without SP could be due to an extremely fast and strong HR that immediately blocks spread of virus particles; therefore, we tested the HR-inducing activity with two other in planta expression assays, virus inoculation and agroinfiltration. Recombinant virus particles were obtained from systemically infected $N$. clevelandii leaves and inoculated on potato. After 5 days, the primary inoculated leaves of $R 4$ plants showed necrosis when inoculated with recombinant virus particles derived from pGR106-Avr4 ${ }^{1-287}$, but there was no response upon inoculation with particles from pGR106-Avr4 ${ }^{25-287}$ or pGR106 (Supplementary Fig. S2). Bintje showed no response in the primary inoculated leaves with any of the constructs but always showed systemic virus spread. Systemic virus spread was also observed in $R 4$ plants inoculated with pGR106-Avr4 ${ }^{25-287}$ or pGR106 but not in $R 4$ plants inoculated with pGR106-Avr4 $4^{1-287}$. As in the agroinfection assay, the SP seems to be required for elicitor activity. For agroinfiltration, Avr4 ${ }^{1-287}$ and $\mathrm{Avr} 4^{25-287}$ were cloned in the binary vector pGRAB and transformed into $A$. tumefaciens AGL1. Infiltration in leaves of $R 4$ plants resulted in an HR within 2 dpi regardless of the presence or absence of the SP (Fig. 4B). Infiltration in Bintje $(r O)$ and $N$. benthamiana showed no responses and was comparable with the empty vector control. In contrast, the positive control, pGRAB-CRN2, elicited responses on all tested plants (Fig. 4B). Infiltration with a strain carrying the empty vector pGRAB gave no response. These results show that the different in planta expression systems gave conflicting data with respect to the requirement for the SP but the conclusion that PiAvr4 is an elicitor of HR specifically on plants carrying $R 4$ was substantiated.

\section{The RXLR-dEER motif is not required for HR-inducing activity of PiAvr4.}

The observation that secretion of PiAvr4 to the extracellular space does not abolish elicitor activity is in conflict with the assumption that Phytophthora spp. deliver the RXLR-dEER effectors inside the host cell at the site where they are presumed to perform their function. We may assume that in planta expression of the full-length PiAvr4 construct (pGR106-Avr4 ${ }^{1-}$ ${ }^{287}$ ) or the construct with the PR1a SP (pGR106-Avr4 ${ }^{\text {SP(PR1a)-25- }}$ ${ }^{287}$ ) results in maturation of the protein in the endoplasmic reticulum and the Golgi, followed by secretion from the cell whereby the SP is removed. If there is no further processing after cleavage of the SP, the mature PiAvr4 retains the RXLRdEER motif. Because this motif could be responsible for translocating PiAvr4 across the membrane to an intracellular location, we generated and tested constructs in which a region of 41 aa (25 to 65 ) comprising the RXLR-dEER motif was deleted. Agroinfection with pGR106-Avr4 ${ }^{\mathrm{SP}(\mathrm{PR} 1 \mathrm{a})-66-287}$ resulted in a strong necrotic response, specifically on $R 4$ plants. This response was comparable with the response with the full-length construct pGR106-Avr4 ${ }^{1-287}$ or pGR106-Avr4 ${ }^{\text {SP(PR1a)-25-287 }}$ (Fig. 4A). This shows that, in these agroinfection assays, the RXLRdEER motif neither stimulates nor prevents elicitor activity of PiAvr4. The finding that the absence of the RXLR-dEER motif does not abolish elicitor activity could point to extracellular recognition of PiAvr4, imply another re-uptake mechanism that is unknown, or indicate that some PiAvr4 is mistargeted during secretion and retained in the cell.

\section{PiAvr4 homologs.}

BLASTN searches of the $P$. infestans T30-4 genome sequence confirmed the presence of the two alleles that we identified in this study. In addition, a number of distant homologs were retrieved. These are located on other supercontigs and, similar to PiAvr4, these homologs have the HTS and belong to the RXLR-dEER superfamily.

Southern blot hybridizations and PCR amplifications on genomic DNA isolated from a variety of Phytophthora spp. revealed PiAvr4 homologs in the closely related species $P$. phaseoli, $P$. andina, $P$. mirabilis, and $P$. ipomoeae but, in species belonging to other clades, no homologs could be identified. The lack of Southern hybridization of PiAvr4 to P. sojae and $P$. ramorum DNA was supported by the apparent absence (by BLASTN) of a homologous DNA sequence in the genome sequences of these oomycetes and $H$. parasitica. Nevertheless, a TBLASTN search in Phytophthora EST sequence databases revealed the presence of a $P$. sojae EST exhibiting modest similarity to PiAvr4. This EST, named 3-9f-HA (accession AY183415), encodes an RXLR-dEER protein and corresponds to a sequence on Scaffold 9 of the $P$. sojae genome (sequence assembly 3.0) (Qutob et al. 2002). In total, five close homologs of PiAvr4 were identified by BLASTP searches in the genomes of $P$. infestans, $P$. sojae, and $P$. ramorum (E value $<1 \mathrm{e}-5$, sequence identity $>30 \%$ ). In the $H$. parasitica genome sequences, no homologs were detected.

\section{PiAvr4 polymorphism in $P$. infestans field isolates.}

The frame shift mutation in the virulent allele of strain T30-4 likely leads to a nonfunctional Avr4 protein. To investigate the allele variation in the $P$. infestans population and to correlate this with the AVR4 phenotype, we analyzed PiAvr4 alleles in field isolates. PCR amplification from genomic DNA of T30-4 with PiAvr4-specific primers resulted solely in fragments derived from the virulent or avirulent allele at the Avr4 locus. PiAvr4specific primers were used to amplify PiAvr4 alleles from genomic DNA and the amplicons were cloned and sequenced. The primers match to the first and the last 20 nucleotides of the ORF and, as a consequence, SNP that may occur in regions 1 to 20 and 845 to 864 cannot be identified. From 15 isolates, 16 different alleles were cloned, I to XVI, and 18 polymorphic sites were found, 17 of which were already identified in the two alleles of T30-4 (Supplementary Fig. S3). Of the 16 alleles, only 4 (I to IV) have a full-length ORF (Fig. 5). All isolates that are avirulent on $R 4$ plants have at least one allele with a full-length ORF. In contrast, none of the isolates that are virulent on $R 4$ have an intact copy of PiAvr4. The absence of alleles with a full-length ORF was confirmed by direct sequencing and cloning of the PCR products generated from genomic DNA. Direct sequencing of PCR products generated from genomic DNA of avirulent strains resulted in unreadable chromatograms because of mixtures of avirulent and frame-shifted virulent alleles. This was the case, for example, with NL88133 which, in addition to allele I, is known to have a virulent allele based on genetic analysis (van der Lee et al. 2001) and Southern hybridization. The virulent isolates with only one identified allele could be homozygous at the Avr4 locus, as expected for NL80029 and NL88069. This is supported by the finding that PH051G10, the EST that originates from NL88069, is identical to allele XIII cloned from NL88069. Several of the isolates tested were obtained prior to the introduction of the A2 mating type in Europe and belong to the 'old' clonal population. Despite their uniform US-1 genotype, these isolates have different PiAvr4 alleles, and the allele distribution is consistent with their phenotype. The multiple alleles in isolates UK7824 and UK7818 could be the result of gene duplication or reflect polyploidy, a known phenomenon in P. infestans (Tooley and Therrien 1987). One of the two 
Ecuadorian (EC3364) isolates was originally isolated from tree tomato (S. betaceum) (Adler et al. 2004) but is pathogenic on potato.

\section{DISCUSSION}

Through a combined approach of genetic linkage mapping (van der Lee et al. 2001), transcriptional profiling (Guo et al. 2006), and BAC marker landing (Whisson et al. 2001), we have cloned an $A v r$ gene from $P$. infestans that functions according to the gene-for-gene model with an $R$ gene from $S$. demissum. Isolates carrying PiAvr4 elicit an HR on $R 4$ potato plants, whereas race 4 isolates with a frame-shift mutation in the PiAvr4 ORF are not recognized and can colonize $R 4$ plants. The definitive proof comes from complementation of race 4 isolates with PiAvr4; transgenic race 4 isolates were pathogenic on $r 0$ plants but avirulent on $R 4$ plants, demonstrating that recognition was conferred by a single gene.

In laboratory assays, race 4 isolates with a disrupted PiAvr4 ORF are as virulent as isolates carrying an intact copy of PiAvr4. Therefore, PiAvr4 by itself is not an essential virulence component, although more subtle effects in nature cannot be excluded. Loss of Avr4 is not compensated by close homologs, since these do not exist but could be compensated by sequenceunrelated effectors that are functionally redundant. PiAvr4 belongs to a family of over 500 P. infestans genes encoding potentially secreted proteins containing the RXLR motif (R. H. Y. Jiang, personal communication) (Whisson et al. 2007). Similarly, large families are present in other Phytophthora spp. (Jiang et al. 2008; Tyler et al. 2006) and the downy mildew $H$. parasitica (R. H. Y. Jiang and B. M. Tyler, personal communication). Key features are found in the N-terminus of the proteins: a SP followed by a conserved domain that has two characteristic motifs, RXLR and dEER. The C-terminal domains, however, are highly divergent and, as a consequence, the RXLR-dEER superfamily is one of the most divergent families in the Phytophthora secretome (Jiang et al. 2008). Nevertheless, some of the RXLRdEER proteins do have recognizable orthologs in distantly related Phytophthora spp. (Jiang et al. 2008).

In recent years, evidence has accumulated that, similar to the PEXEL motif in secreted proteins of the malaria parasite Plasmodium falciparum (Przyborski and Lanzer 2004), the RXLR-dEER domain is an HTS that is responsible for targeting pathogen proteins to the host cytoplasm (Dou et al. 2008b; Whisson et al. 2007). Because all oomycete $A v r$ genes that have been characterized to date encode RXLR-dEER proteins (Bouwmeester et al. 2008), it is anticipated that the HTS plays a crucial role in their function as Avr factors. Moreover, the fact that all known cognate $R$ genes of oomycete $A v r$ genes encode intracellular NBS-LRR proteins (Dangl and Jones 2001) makes it conceivable that oomycete Avr factors are targeted to the host cell. In recent years, evidence that not only bacterial plant pathogens but also fungi (Ellis et al. 2007) deliver effectors to the host cytoplasm, or even the nucleus, is accumulating. Examples are (putative) Avr factors from rust fungi (Catanzariti et al. 2005; Dodds et al. 2004; Kemen et al. 2005) and powdery mildews. Most striking is Blumeria graminis AVRA10, a protein which lacks an SP but is nevertheless secreted by the fungus and targeted to the host nucleus. It forms a complex with the barley R protein MLA10 and WRKY transcription factors, resulting in derepression of PAMP-triggered basal defense (Ridout et al. 2006; Shen et al. 2007). Recently, Whisson and associates (2007) described an elegant approach to demonstrate that intracellular delivery of the oomycete Avr protein Avr3a is necessary for recognition by its cognate $\mathrm{R}$ protein. In that study, the type III secretion system of the bacterial pathogen Pectobacterium atrosepticum was exploited to deliver the C-terminal domain of the Avr protein into the host
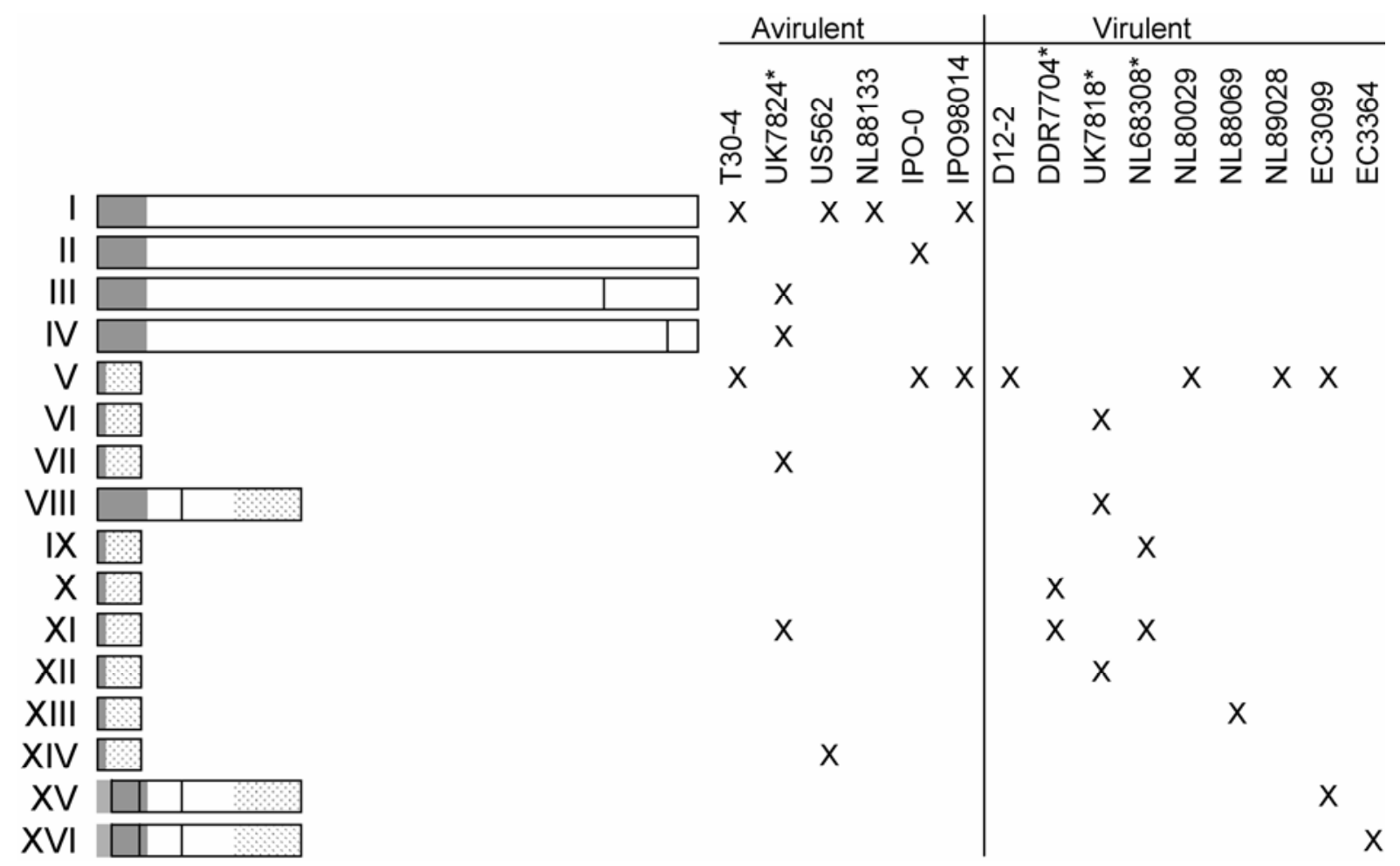

Fig. 5. PiAvr4 alleles identified in Phytophthora infestans field isolates. Shown are the proteins encoded by 16 different alleles numbered I to XVI. PiAvr4 encoded by allele I is shown as a bar with the signal peptide shaded (dark gray). A vertical black line represents an amino acid change with respect to PiAvr4. The dotted area represents an out-of-frame open reading frame. In alleles XV and XVI, the light gray shaded area preceding the bar represents 22 nucleotides, of which the sequence was not determined. The isolates are grouped according to their phenotype on $R 4$ plants. Isolates marked by an asterisk (*) originate from the clonal population that existed prior to the introduction of the A2 mating type in Europe. 
cell. By comparing wild-type strains and type III secretion mutants of P. atrosepticum, it could be shown that Avr3a has to be targeted to the inside of the cell in order to be recognized by the R protein R3a. Two other recent studies used the Pseudomonas syringae type III secretion system to target ATR13 into Arabidopsis cells (Rentel et al. 2008; Sohn et al. 2007) and both showed that intracellular targeting is also required for recognition of ATR13.

Prior to the discovery of the RXLR-dEER motif, Shan and associates (2004) published the positional cloning of the first oomycete $A v r$ gene. To prove that the Phytophthora sojae $A v r l b-1$ gene was indeed an Avr gene, they infiltrated Avrlb protein, obtained by heterologous expression, into the apoplast (Shan et al. 2004). The $R$-gene-mediated response that was observed suggested extracellular recognition of Avr1b. More recent data have shown that transformation of a virulent $P$. sojae race with $A v r l b-1$ can complement the avirulent phenotype whereas $A v r l b-1$ mutated in the RXLR or dEER motif cannot (Dou et al. 2008b), thus suggesting host cell targeting by virtue of the HTS and intracellular recognition of the Avrlb protein. In retrospect, the initial observations by Shan and associates (2004) point to an intrinsic transport mechanism embodied within Avr1b-1 and independent of other pathogen proteins, as has been suggested for AvrM and AvrP4 from the flax rust pathogen Melampsora lini (Catanzariti et al. 2005). Hypothetically, an RXLR-dEER effector could be capable of inducing membrane channels or modulating the host endocytosis machinery for its own benefit. Interestingly, the Tyler lab has recently shown that the HTS of Avr1b by itself can govern uptake of Avr1b into plant cells (Dou et al. 2008b; Govers and Bouwmeester 2008).

As we have observed in this study, the transient in planta expression system that is used to monitor effector activity can be misleading. Because $R 4$ is not cloned, we were constrained to perform our assays on potato differentials. Hence, we chose a method that was previously optimized for potato (i.e., PVX agroinfection) (Vleeshouwers et al. 2006). In these agroinfection assays, we never saw a response with PiAvr4 when expressed without an SP; also, the virus inoculations pointed toward a requirement for an SP. With agroinfiltration, however, there was no difference between a construct with or without SP. In planta expression assays in potato using agroinfection or agroinfiltration are quite challenging. With agroinfection, PVX replication rates and stability of the constructs may vary. With agroinfiltration, there are often nonspecific responses and the success rate is highly dependent on the A. tumefaciens strain, the potato line, and the conditions of the plants. The A. tumefaciens strain that we used though, did not give nonspecific responses on potato. Others who have used different in planta expression assays in parallel also found conflicting results with respect to the requirement of an SP. In some cases when the $R$ gene was available, agroinfection and coinfiltration of $A v r$ and $R$ gene was used (Armstrong et al. 2005); in other cases, particle bombardment on plants with an $R$ locus (Allen et al. 2004; Armstrong et al. 2005; Dou et al. 2008a; Rehmany et al. 2005). Qutob and associates (2006) showed that particle bombardment can distinguish between intra- and extracellular recognition. They tested a NEPlike protein (NLP) on Arabidopsis and, as expected for NLP, only constructs with SP were recognized. In the case of particle bombardment of $R 3 a$ plants with $A v r 3 a$, only constructs lacking the SP elicited an HR (Armstrong et al. 2005), leading to the conclusion that $A v r 3 a$ is recognized intracellularly. In later experiments, however, coinfiltration of $A v r 3 a$ and $R 3 a$ in $N$. benthamiana showed no differences in necrotic response between constructs with and without SP (Bos et al. 2006). In the case of particle bombardment of Arabidopsis with $H$. parasitica $A T R I^{N d W s B}$, the cell death response was stronger when the SP was removed (Rehmany et al. 2005) whereas H. parasitica
ATR13 with and without SP gave similar responses (Allen et al. 2004). However, when ATR13 with SP was targeted by Pseudomonas syringae via type III secretion into Arabidopsis cells, it did not elicit an HR (Rentel et al. 2008).

In the PVX agroinfection assays, PiAvr4 without SP does not elicit an HR in $R 4$ plants. This suggests that an unprocessed, intracellular PiAvr4 effector does not activate defense and that the SP is required to facilitate secretion of PiAvr4 to reach the site where receptors are located. In contrast, the agroinfiltration assays show unequivocal recognition of PiAvr4 with and without the SP, suggesting that the protein is also recognized inside the plant cell. Because of these conflicting data, we cannot draw firm conclusions about the primary site of recognition of PiAvr4, extracellular or intracellular. However, we can conclude that the presence or absence of the RXLR-dEER domain did not change the response. If, similar to the HTS of Avr1b (Dou et al. $2008 \mathrm{~b}$ ), the HTS of Avr4 by itself is capable of directing the uptake, then our experimental data are in favor of extracellular recognition. However, this needs further experimentation.

What, then, happens in a natural infection? And what is the function of the RXLR-dEER domain if PiAvr4 is not necessarily targeted to the cytoplasm? One could speculate that the host target of PiAvr4 may be a plant protein that is located extracellularly. We do not know the nature of R4, but it may differ from other late blight $\mathrm{R}$ proteins and resemble, for example, receptor-like kinases like the $\mathrm{Cf}$ or Xa21 $\mathrm{R}$ proteins (Dangl and Jones 2001) that have a transmembrane region and an extracellular LRR domain. Alternatively, the host target may be a plant protein that mediates interaction between PiAvr4 and R4 (i.e., a so-called virulence target). The first identified putative virulence target for an RXLR-dEER effector (IPI-O) is a membrane-spanning protein with an extracellular domain with binding affinity for IPI-O and an intracellular kinase (Gouget et al. 2006). Another possibility to be considered when using transient in planta assays is re-uptake of PiAvr4 after secretion. However, because deletion of the RXLR-dEER domain from a construct with SP did not change the response, re-uptake mediated by the RXLR-dEER domain is not likely to occur. A third alternative may be that PiAvr4 has multiple host proteins as targets, some of which may be located intracellularly and others extracellularly, and that interaction with an extracellular target is perceived by R4. This may explain why the RXLR-dEER domain is intact and has not degraded through drift.

It is noteworthy to mention that the virulent alleles of PiAvr4 have disrupted ORF, in contrast to other oomycete Avr genes where point mutations or transcript levels determine the phenotype (Bouwmeester et al. 2008). The fact that PiAvr4 does not seem to be crucial for virulence raises the question if, in a compatible interaction between $r O$ plants and isolates expressing PiAvr4, PiAvr4 has a function as effector and is internalized. Even though the RXLR motif and the dEER motif in PiAvr4 are conserved, one cannot exclude the possibility that mutations surrounding the motifs have disabled the HTS and uptake is no longer possible. Recent experimental evidence showed that residues adjacent to the RXLR motif are crucial for the effector trafficking (Dou et al. 2008b). HMM scores of RXLR-dEER domains vary considerably and could have a predictive value for the function of the HTS (Dou et al. 2008b; Jiang et al. 2008). In Phytophthora sojae and P. ramorum, almost $10 \%$ of the predicted RXLR-dEER genes are truncated (Jiang et al. 2008) and, in P. infestans, many partial ORF are also found (R. H. Y. Jiang, personal communication). Apparently, this reservoir of truncated RXLR-dEER genes does not harm the organism. PiAvr4 is an example of a gene that is expressed in several field isolates but is mutated without an obvious fitness penalty in other isolates. 
To address the site of recognition of PiAvr4 and the role of the RXLR-dEER domain in PiAvr4, more detailed experiments are required. As has been shown for $P$. infestans Avr3a (Whisson et al. 2007) and P. sojae Avrlb (Dou et al. 2008b), cell biological analyses using fluorescent tags, such as monomeric red fluorescent protein (mRFP) or green fluorescent protein (GFP), will help to localize PiAvr4, and mutational analysis of the RXLRdEER domain will address the role of the HTS in PiAvr4.

\section{MATERIALS AND METHODS}

\section{$P$. infestans isolates and nomenclature of phenotypes and genes.}

The cross 71 mapping population, the two parental isolates NL80029 and NL88133, and the F1 progeny were described previously (Drenth et al. 1995; Guo et al. 2006; Jiang et al. 2006; van der Lee et al. 1997). The genomic T30-4 BAC library was described by Whisson and associates (2001). The nomenclature of phenotypes is according to van der Lee and associates (2001). Isolates avirulent (among others NL88133 and T30-4) or virulent (among others NL80029) on $R 4$ plants have the AVR4 and avr4 phenotype, respectively. Genes and proteins are named according to the system proposed by the Oomycete Molecular Genetics Network (Govers and Gijzen 2006). The gene cloned from the avirulence locus Avr4 is designated as PiAvr4 and the encoded protein as PiAvr4; Piavr4 is the gene located at the recessive allele. $P$. infestans field isolates were retrieved from our own culture collection or provided by colleagues.

\section{$P$. infestans growth conditions.}

$P$. infestans was maintained on rye sucrose agar (RSA) (Caten and Jinks 1968) at $18^{\circ} \mathrm{C}$. Germinated cysts for RNA isolation were obtained as described by van West and associates (1998). Zoospores were released by flooding 10-day-old mycelium with ice cold water followed by $3 \mathrm{~h}$ of incubation at $4^{\circ} \mathrm{C}$. Released zoospores were encysted by shaking and germinated in water for 2 to $4 \mathrm{~h}$ at room temperature. Germinated cysts were concentrated by centrifugation for $5 \mathrm{~min}$ at 4,000 $\times$ $g$, frozen in liquid $\mathrm{N}_{2}$, and stored at $-80^{\circ} \mathrm{C}$. Mycelium for DNA and RNA isolation was obtained by growing $P$. infestans in liquid clarified rye sucrose (RS) medium for 7 days at $18^{\circ} \mathrm{C}$. Dried mycelium was quickly frozen and stored at $-80^{\circ} \mathrm{C}$.

\section{Nucleic acid manipulations.}

DNA and RNA isolation were performed according to established procedures. DNA extraction buffer (0.2 M Tris, $\mathrm{pH} 8.5$; $0.25 \mathrm{M} \mathrm{NaCl}$; $25 \mathrm{mM}$ EDTA; and $2 \%$ sodium dodecyl sulfate) and 3-mm glass beads were added to frozen mycelium and the mixture was ground in a FastPrep instrument (Qbiogene, Carlsbad, CA, U.S.A.). Three phenol/chloroform extractions were performed, followed by an RNAse treatment and DNA precipitation. For RNA isolation, glass beads and TRIzol (Invitrogen, Carlsbad, CA, U.S.A.) were added to the frozen samples and these were homogenized in the Fastprep instrument. Further extraction was performed according to the manufacturers' procedure.

For RT-PCR, we used the SuperScript III one-step RT-PCR system (Invitrogen). Primer combinations RTAvr4F and RTAvr4R plus RTActAF and RTActAR were used to amplify PiAvr4 and actin gene ActA, respectively. cDNA synthesis was performed at $50^{\circ} \mathrm{C}$ for $30 \mathrm{~min}$ followed by amplification cycles of $15 \mathrm{~s}$ at $94^{\circ} \mathrm{C}, 30 \mathrm{~s}$ at $50^{\circ} \mathrm{C}$, and $30 \mathrm{~s}$ at $74^{\circ} \mathrm{C}$. In all, 27 cycles were required for ActA amplification and 32 cycles for PiAvr4 amplification.

DNA digestion, agarose gel electrophoresis, Southern blotting to Hybond-N+ membranes (Amersham Biosciences. Piscataway, NJ, U.S.A.), and hybridizations were performed according to standard procedures (Sambrook and Russell 2001). Hybridization probes were ${ }^{32} \mathrm{P}$-labeled by random primer labeling (Prime-a-gene labeling system; Promega, Madison, WI, U.S.A.).

\section{BAC library screening and cloning.}

The BAC library was screened with Avr4-linked AFLP markers (van der Lee et al. 2001) using a three-dimensional pooling strategy (Whisson et al. 2001). Hybridization of the BAC library and BAC fingerprint blots, BAC DNA isolation and digestion, and BAC contig building were performed as described (Jiang et al. 2005, 2006). Hybridization probes were a 295-bp fragment from EST PH051G10 (National Center for Biotechnology Information accession number CV920942) and a 465-bp BamHI-SalI restriction fragment located at the 3' UTR of PiAvr4. For subcloning and sequencing, we used standard procedures (Sambrook and Russell 2001). Sequence data have been submitted to GenBank under accession numbers EF672354 and EF672355.

\section{Cloning of PiAvr4 alleles.}

PiAvr4 alleles were amplified from genomic DNA isolated from different $P$. infestans isolates by $P f u$ proofreading polymerase (Promega) with primers PiAvr4F and PiAvr4R. DNA was amplified in a thermal cycler in 35 cycles of $60 \mathrm{~s}$ at $94^{\circ} \mathrm{C}$, $60 \mathrm{~s}$ at $55^{\circ} \mathrm{C}$, and $150 \mathrm{~s}$ at $72^{\circ} \mathrm{C}$. The obtained fragments were gel-purified and cloned into the pGEM-T Easy vector (Promega) according to the manufacturer's descriptions. Direct sequencing of PCR bands was performed using primers $\mathrm{PiAvr} 4$ seqF and PiAvr4seqR. Cloned fragments were sequenced using standard M13 primers. DNA sequences were assembled and analyzed using the Vector NTI 10 software package.

\section{DNA transformation of $P$. infestans.}

$P$. infestans isolates D12-2 and T35-3 were stably transformed using the polyethylene glycol protoplast transformation protocol described by van West and associates (1998). Protoplasts were obtained by a mixture of lysing enzymes from Trichoderma harzianum (Sigma-Aldrich Chemi, Zwijndrecht, The Netherlands) ( $5 \mathrm{mg} \mathrm{ml}^{-1}$ ) and cellulase from $T$. reesei (Sigma-Aldrich) $\left(2 \mathrm{mg} \mathrm{ml} \mathrm{m}^{-1}\right)$. For transformation, we constructed plasmid pTA23.9 that carries PiAvr4 and a geneticin (G418) resistance gene. To generate pTA23.9, a 2,890-bp BamHI fragment derived from BAC01E13 and carrying PiAvr4 (Fig. 2) was cloned into pTH209SK, a vector with a pBS II SK+ backbone that caries a 5' HSP70::NPTII::3' HAM34 cassette. Transformants were selected on RSA supplemented with geneticin at 3 $\mu \mathrm{g} \mathrm{ml}^{-1}$. Transformants appeared after 9 to 20 days.

\section{Plant genotypes and growth conditions.}

R4 breeding line Cebeco44-31-5 (Black et al. 1953; Mastenbroek 1953) from the Mastenbroek differentials and cv. Isola $(R 4)$ were used for infection assays. As control plants, cv. Bintje $(r O)$ and breeding line SW8540-025 (R3a) (Huang et al. $2005)$ were used. Plants were grown in vitro for 4 weeks in climate chambers on MS30 medium (16 h of light and $8 \mathrm{~h}$ of darkness, $20^{\circ} \mathrm{C}$ ) and transferred to potting soil in a greenhouse, where they were grown for an additional 4 to 6 weeks $(16 \mathrm{~h}$ if light at $21^{\circ} \mathrm{C}$ and $8 \mathrm{~h}$ of darkness at $19^{\circ} \mathrm{C}$ ).

\section{Virulence assays.}

Virulence phenotypes of $P$. infestans isolates and transformants were determined in assays performed as described by Vleeshouwers and associates (1999). A zoospore suspension (10 $\mu \mathrm{l}$ of 100 spores $\mu \mathrm{l}^{-1}$ ) was spotted on the abaxial side of detached potato leaves. Lesion development was monitored up to $6 \mathrm{dpi}$. Infection efficiency and lesion growth rate were determined as described (Vleeshouwers et al. 1999). 
Binary constructs, agroinfection, and agroinfiltration.

For in planta expression of PiAvr4, binary PVX constructs were made in vector pGR106 (Jones et al. 1999). Fragments were amplified by PCR and overlap PCR with the appropriate primers (Supplementary Tables S2 and S4). The amplicons were digested and cloned into pGR106. The constructs were than transformed to A. tumefaciens GV3101, which carries the pSoup helper plasmid (Hellens et al. 2000).

Agroinfection assays were performed as described for potato (Vleeshouwers et al. 2006) and Nicotiana spp. (Huitema et al. 2005). Briefly, A. tumefaciens strains containing the binary PVX constructs were grown for 2 days on LBman agar medium (10 g of bacto trypton, $5 \mathrm{~g}$ of yeast extract, $2.5 \mathrm{~g}$ of $\mathrm{NaCl}, 10 \mathrm{~g}$ of mannitol, and $15 \mathrm{~g}$ of daishin agar per liter) supplemented with antibiotics (rifampicin at $10 \mu \mathrm{g} \mathrm{ml}^{-1}$ and kanamycin at $100 \mu \mathrm{g}$ $\mathrm{ml}^{-1}$ ). Toothpicks were used to transfer bacteria to the leaves and to pierce the leaf, creating wounded tissue. Responses were monitored up to 4 weeks postinoculation.

For agroinfiltration assays, PiAvr4 constructs were cloned in vector pGRAB (Whisson et al. 2007). The obtained constructs were than transformed into A. tumefaciens AGL1, which carries the pSoup helper plasmid (Hellens et al. 2000).

Agroinfiltration assays were performed as described previously (van der Hoorn et al. 2000). Briefly, A. tumefaciens strains containing the binary constructs were grown in $100 \mathrm{ml}$ of YEB medium ( $5 \mathrm{~g}$ of beef extract, $5 \mathrm{~g}$ of bacto trypton, $5 \mathrm{~g}$ of sucrose, and $1 \mathrm{~g}$ of yeast extract per liter) supplemented with $20 \mu \mathrm{M}$ acetosyringone, $10 \mathrm{mM}$ MES, rifampicin at $10 \mu \mathrm{g}$ $\mathrm{ml}^{-1}$, and kanamycin at $100 \mu \mathrm{g} \mathrm{ml}{ }^{-1}$. When the optical density at $600 \mathrm{~nm}\left(\mathrm{OD}_{600}\right)$ reached 0.8 , cells were centrifuged and resuspended in MMA ( $5 \mathrm{~g}$ of MS salts, $20 \mathrm{~g}$ of sucrose, and 1.95 $\mathrm{g}$ of MES per liter, $\mathrm{pH}$ 5.6) to an $\mathrm{OD}_{600}$ of 2.0. Virulence was induced by incubating the resuspended bacteria at room temperature for $1 \mathrm{~h}$. Leaves of 2- to 3-week-old potato plants were infiltrated with the bacterial suspension. Responses were monitored up to 1 week postinoculation.

\section{ACKNOWLEDGMENTS}

We thank M. ter Maat for performing the initial polymorphism analyses, R. Weide for help with transformations, D. Baulcombe for providing pGR106, S. Kamoun for pGR106-CRN2, D.-J. Huigen for plant material, H. Smid and B. Essenstam for support in the greenhouse, and J. Ristaino and $\mathrm{T}$. van den Bosch for kindly providing field isolates. This project was cofinanced by the Centre for BioSystems Genomics (CBSG) which is part of the Netherlands Genomics Initiative/Netherlands Organisation for Scientific Research, the Wageningen University Interdisciplinary Research and Education Fund (INREF) in the framework of the joint WU-CAAS Ph.D. training program and the Technology Foundation STW (WPB5498).

\section{LITERATURE CITED}

Adler, N. E., Erselius, L. J., Chacon, M. G., Flier, W. G., Ordonez, M. E., Kroon, L., and Forbes, G. A. 2004. Genetic diversity of Phytophthora infestans sensu lato in Ecuador provides new insight into the origin of this important plant pathogen. Phytopathology 94:154-162.

Allen, R. L., Bittner-Eddy, P. D., Grenville-Briggs, L. J., Meitz, J. C., Rehmany, A. P., Rose, L. E., and Beynon, J. L. 2004. Host-parasite coevolutionary conflict between Arabidopsis and downy mildew. Science 306:1957-1960.

Armstrong, M. R., Whisson, S. C., Pritchard, L., Bos, J. I. B., Venter, E., Avrova, A. O., Rehmany, A. P., Bohme, U., Brooks, K., Cherevach, I., Hamlin, N., White, B., Fraser, A., Lord, A., Quail, M. A., Churcher, C., Hall, N., Berriman, M., Huang, S., Kamoun, S., Beynon, J. L., and Birch, P. R. J. 2005. An ancestral oomycete locus contains late blight avirulence gene Avr3a, encoding a protein that is recognized in the host cytoplasm. Proc. Natl. Acad. Sci. U.S.A. 102:7766-7771.

Ballvora, A., Ercolano, M. R., Weiss, J., Meksem, K., Bormann, C. A., Oberhagemann, P., Salamini, F., and Gebhardt, C. 2002. The R1 gene for potato resistance to late blight (Phytophthora infestans) belongs to the leucine zipper/NBS/LRR class of plant resistance genes. Plant J.
30:361-371.

Birch, P. R. J., Rehmany, A. P., Pritchard, L., Kamoun, S., and Beynon, J. L. 2006. Trafficking arms: Oomycete effectors enter host plant cells. Trends Microbiol. 14:8-11.

Black, W., Mastenbroek, C., Mills, W. R., and Peterson, L. C. 1953. A proposal for an international nomenclature of races of Phytophthora infestans and of genes controlling immunity in Solanum demissum derivates. Euphytica 2:173-179.

Bos, J. I., Kanneganti, T. D., Young, C., Cakir, C., Huitema, E., Win, J., Armstrong, M., Birch, P. R. J., and Kamoun, S. 2006. The C-terminal half of Phytophthora infestans RXLR effector AVR3a is sufficient to trigger R3a-mediated hypersensitivity and suppress INF1-induced cell death in Nicotiana benthamiana. Plant J. 48:165-176.

Bouwmeester, K., van Poppel, P. M. J. A., and Govers, F. 2008. Genome biology cracks enigmas of oomycete plant pathogens. Pages 102-134 in: Annual Plant Review, Vol. 34: Molecular Aspects of Plant Disease Resistance. J. E. Parker, ed. Wiley-Blackwell, New York.

Catanzariti, A.-M., Dodds, P. N., Lawrence, G. J., Ayliffe, M. A., and Ellis, J. G. 2005. Haustorially expressed secreted proteins from flax rust are highly enriched for avirulence elicitors. Plant Cell 18:243-256.

Catanzariti, A.-M., Dodds, P. N., and Ellis, J. G. 2007. Avirulence proteins from haustoria-forming pathogens. FEMS (Fed. Eur. Microbiol. Soc.) Microbiol. Lett. 269:181-188.

Caten, C. E., and Jinks, J. L. 1968. Spontaneous variability of single isolates of Phytophthora infestans. I. Cultural variation. Can. J. Bot. 46:329-347.

Chisholm, S. T., Coaker, G., Day, B., and Staskawicz, B. J. 2006. Host-microbe interactions: Shaping the evolution of the plant immune response. Cell 124:803-814.

Dangl, J. L., and Jones, J. D. G. 2001. Plant pathogens and integrated defence responses to infection. Nature 411:826-833.

Dodds, P. N., Lawrence, G. J., Catanzariti, A. M., Ayliffe, M. A., and Ellis, J. G. 2004. The Melampsora lini AvrL567 avirulence genes are expressed in haustoria and their products are recognized inside plant cells. Plant Cell 16:755-768.

Dou, D., Kale, S. D., Wang. X., Chen, Y., Wang, Q., Wang, X., Jiang, R. H. Y., Arredondo, F. D., Anderson, R. G., Thakur, P. B., McDowell, J. M. Wang, Y. and Tyler, B. M. 2008a. Conserved C-terminal motifs required for avirulence and suppression of cell death by Phytophthora sojae effector Avr1b. Plant Cell 20:1118-1133.

Dou, D., Kale, S. D., Wang, X., Jiang, R. H. Y., Bruce, N. A., Arredondo, F. D., Zhang, X., and Tyler, B. M. 2008b. RXLR-mediated entry of Phytophthora sojae effector Avr1b into soybean cells does not require pathogen encoded machinery. Plant Cell 20: 1930-1947.

Drenth, A., Janssen, E. M., and Govers, F. 1995. Formation and survival of oospores of Phytophthora infestans under natural conditions. Plant Pathol. 44:86-94

Ellis, J. G., Dodds, P. N., and Lawrence, G. J. 2007. The role of secreted proteins in diseases of plants caused by rust, powdery mildew and smut fungi. Curr. Opin. Microbiol. 10:326-331.

Flor, H. H. 1971. Current status of the gene-for-gene concept. Annu. Rev. Phytopathol. 9:275-296.

Gouget, A., Senchou, V., Govers, F., Sanson, A., Barre, A., Rougé, P., Pont-Lezica, R., and Canut, H. 2006. Lectin receptor kinases participate in protein-protein interactions to mediate plasma membrane-cell wall adhesions in Arabidopsis. Plant Physiol. 140:81-90.

Govers, F., and Bouwmeester, K. 2008. Effector trafficking: RXLR-dEER as extra gear for delivery into plant cells. Plant Cell 20:1728-1730.

Govers, F., and Gijzen, M. 2006. Phytophthora genomics: The plant destroyers' genome decoded. Mol. Plant-Microbe Interact. 19:1295-1301.

Govers, F., and Latijnhouwers, M. 2004. Late blight. Pages 1-5 in: Encyclopedia of Plant and Crop Science. R. M. Goodman, ed. Dekker Encyclopedias, New York.

Guo, J., Jiang, R. H. Y., Kamphuis, L. G., and Govers, F. 2006. a cDNAAFLP based strategy to identify transcripts associated with avirulence in Phytophthora infestans. Fungal Genet. Biol. 43:111-123.

Hellens, R. P., Edwards, E. A., Leyland, N. R., Bean, S., and Mullineaux, P. M. 2000. pGreen: A versatile and flexible binary Ti vector for Agrobacterium-mediated plant transformation. Plant Mol. Biol. 42:819-832.

Huang, S. W., van der Vossen, E. A. G., Kuang, H. H., Vleeshouwers, V. G. A. A., Zhang, N. W., Borm, T. J. A., van Eck, H. J., Baker, B., Jacobsen, E., and Visser, R. G. F. 2005. Comparative genomics enabled the isolation of the $R 3 a$ late blight resistance gene in potato. Plant J. 42:251-261.

Huitema, E., Vleeshouwers, V. G. A. A., Cakir, C., Kamoun, S., and Govers, F. 2005. Differences in intensity and specificity of hypersensitive response induction in Nicotiana spp. by INF1, INF2A, and INF2B of Phytophthora infestans. Mol. Plant-Microbe Interact. 18:183-193.

Jiang, R. H. Y., Dawe, A. L., Weide, R., van Staveren, M., Peters, S., Nuss, D. L., and Govers, F. 2005. Elicitin genes in Phytophthora infestans are clustered and interspersed with various transposon-like elements. Mol. Genet. Genomics 273:20-32. 
Jiang, R. H. Y., Weide, R., van De Vondervoort, P. J. I., and Govers, F. 2006. Amplification generates modular diversity at an avirulence locus in the pathogen Phytophthora. Genome Res. 16:827-840.

Jiang, R. H. Y., Tripathy, S., Govers, F., and Tyler, B. M. 2008. The RXLR effector reservoir in two Phytophthora species is a single rapidly evolving super-family with 700 members. Proc. Natl. Acad. Sci. U.S.A. 105:4874-4879.

Jones, D. A., and Takemoto, D. 2004. Plant innate immunity-direct and indirect recognition of general and specific pathogen-associated molecules. Curr. Opin. Immunol. 16:48-62.

Jones, L., Hamilton, A. J., Voinnet, O., Thomas, C. L., Maule, A. J., and Baulcombe, D. C. 1999. RNA-DNA interactions and DNA methylation in post-transcriptional gene silencing. Plant Cell 11:2291-2302.

Kemen, E., Kemen, A. C., Hempel, U., Mendgen, K., Voegele, R. T., Rafiqi, M., and Hahn, M. 2005. Identification of a protein from rust fungi transferred from haustoria into infected plant cells. Mol. PlantMicrobe Interact. 18:1130-1139.

Kjemtrup, S., Nimchuk, Z., and Dangl, J. L. 2000. Effector proteins of phytopathogenic bacteria: Bifunctional signals in virulence and host recognition. Curr. Opin. Microbiol. 3:73-78.

Malcolmson, J. F., and Black, W. 1966. New $R$ genes in Solanum demissum lindl. and their complementary races of Phytophthora infestans (Mont.) de Bary. Euphytica 15:199-203.

Mastenbroek, C. 1953. Experiments on the inheritance of blight immunity in potatoes derived from Solanum demissum Lindl. Euphytica 2:197-206.

McLeod, A., Smart, C. D., and Fry, W. E. 2004. Core promoter structure in the oomycete Phytophthora infestans. Eukaryot. Cell 3:91-99.

Nürnberger, T., Brunner, F., Kemmerling, B., and Piater, L. 2004. Innate immunity in plants and animals: Striking similarities and obvious differences. Immunol. Rev. 198:249-266.

Pieterse, C. M., van West, P., Verbakel, H. M., Brasse, P. W., van den BergVelthuis, G. C., and Govers, F. 1994. Structure and genomic organization of the ipiB and ipiO gene clusters of Phytophthora infestans. Gene 138:67-77.

Przyborski, J., and Lanzer, M. 2004. The malarial secretome. Science 306:1897-1898.

Qutob, D., Kamoun, S., and Gijzen, M. 2002. Expression of a Phytophthora sojae necrosis-inducing protein occurs during transition from biotrophy to necrotrophy. Plant J. 32:361-373.

Qutob, D., Kemmerling, B., Brunner, F., Kufner, I., Engelhardt, S., Gust, A. A., Luberacki, B., Seitz, H. U., Stahl, D., Rauhut, T., Glawischnig, E., Schween, G., Lacombe, B., Watanabe, N., Lam, E., Schlichting, R., Scheel, D., Nau, K., Dodt, G., Hubert, D., Gijzen, M., and Nurnberger, T. 2006. Phytotoxicity and innate immune responses induced by Nep1like proteins. Plant Cell 18:3721-3744.

Randall, T. A., Dwyer, R. A., Huitema, E., Beyer, K., Cvitanich, C., Kelkar, H., Ah Fong, A. M. V., Gates, K., Roberts, S., Yatzkan, E., Gaffney, T., Law, M., Testa, A., Torto-Alalibo, T., Zhang, M., Zheng, L., Mueller, E., Windass, J., Binder, A., Birch, P. R. J., Gisi, U., Govers, F., Gow, N. A., Mauch, F., Van West, P., Waugh, M. E., Yu, J., Boller, T., Kamoun, S., Lam, S. T., and Judelson, H. S. 2005. Large-scale gene discovery in the oomycete Phytophthora infestans reveals likely components of phytopathogenicity shared with true fungi. Mol. Plant-Microbe Interact. 18:229-243.

Rehmany, A. P., Gordon, A., Rose, L. E., Allen, R. L., Armstrong, M. R., Whisson, S. C., Kamoun, S., Tyler, B. M., Birch, P. R. J., and Beynon, J. L. 2005. Differential recognition of highly divergent downy mildew avirulence gene alleles by $R P P 1$ resistance genes from two Arabidopsis lines. Plant Cell 17:1839-1850.

Rentel, M. C., Leonelli, L., Dahlbeck, D., Zhao, B., and Staskawicz, B. J. 2008. Recognition of the Hyaloperonospora parasitica effector ATR13 triggers resistance against oomycete, bacterial, and viral pathogens. Proc. Natl. Acad. Sci. U.S.A. 105:1091-1096.

Ridout, C. J., Skamnioti, P., Porritt, O., Sacristan, S., Jones, J. D. G., and Brown, J. K. M. 2006. Multiple avirulence paralogues in cereal powdery mildew fungi may contribute to parasite fitness and defeat of plant resistance. Plant Cell 18:2402-2414.

Sambrook, J. J., and Russell, D. W. 2001. Molecular Cloning: A Laboratory Manual. Cold Spring Harbor Laboratory Press, Cold Spring Harbor, NY, U.S.A.

Shan, W., Cao, M., Leung, D., and Tyler, B. M. 2004. The Avr1B locus of Phytophthora sojae encodes an elicitor and a regulator required for avirulence on soybean plants carrying resistance gene Rps1b. Mol. Plant-Microbe Interact. 17:394-403.

Shen, Q.-H., Saijo, Y., Mauch, S., Biskup, C., Bieri, S., Keller, B., Seki, H., Ulker, B., Somssich, I. E., and Schulze-Lefert, P. 2007. Nuclear activity of MLA immune receptors links isolate-specific and basal disease-resistance responses. Science 315:1098-1103.
Sohn, K. H., Lei, R., Nemri, A., and Jones, J. D. G. 2007. The downy mildew effector proteins ATR1 and ATR13 promote disease susceptibility in Arabidopsis thaliana. Plant Cell 19:4077-4090.

Song, J., Bradeen, J. M., Naess, S. K., Raasch, J. A., Wielgus, S. M., Haberlach, G. T., Liu, J., Kuang, H., Austin-Phillips, S., Buell, C. R., Helgeson, J. P., and Jiang, J. 2003. Gene RB cloned from Solanum bulbocastanum confers broad spectrum resistance to potato late blight. Proc. Natl. Acad. Sci. U.S.A. 100:9128-9133.

Tooley, P. W., and Therrien, C. D. 1987. Cytophotometric determination of the nuclear DNA content of 23 Mexican and 18 non-Mexican isolates of Phytophthora infestans. Exp. Mycol. 11:19-26.

Torto, T. A., Li, S., Styer, A., Huitema, E., Testa, A., Gow, N. A. R., van West, P., and Kamoun, S. 2003. EST mining and functional expression assays identify extracellular effector proteins from the plant pathogen Phytophthora. Genome Res. 13:1675-1685.

Tyler, B. M., Tripathy, S., Zhang, X., Dehal, P., Jiang, R. H. Y., Aerts, A., Arredondo, F. D., Baxter, L., Bensasson, D., Beynon, J. L., Chapman, J., Damasceno, C. M. B., Dorrance, A. E., Dou, D., Dickerman, A. W., Dubchak, I. L., Garbelotto, M., Gijzen, M., Gordon, S. G., Govers, F., Grunwald, N. J., Huang, W., Ivors, K. L., Jones, R. W., Kamoun, S., Krampis, K., Lamour, K. H., Lee, M.-K., McDonald, W. H., Medina, M., Meijer, H. J. G., Nordberg, E. K., Maclean, D. J., Ospina-Giraldo, M. D., Morris, P. F., Phuntumart, V., Putnam, N. H., Rash, S., Rose, J. K. C., Sakihama, Y., Salamov, A. A., Savidor, A., Scheuring, C. F., Smith, B. M., Sobral, B. W. S., Terry, A., Torto-Alalibo, T. A., Win, J., Xu, Z., Zhang, H., Grigoriev, I. V., Rokhsar, D. S., and Boore, J. L. 2006. Phytophthora genome sequences uncover evolutionary origins and mechanisms of pathogenesis. Science 313:1261-1266.

van der Hoorn, R. A. L., Laurent, F., Roth, R., and De Wit, P. J. G. M. 2000. Agroinfiltration is a versatile tool that facilitates comparative analyses of $A v r 9 / C f$-9-induced and $A v r 4 / C f$-4-induced necrosis. Mol. Plant-Microbe Interact. 13:439-446.

van der Lee, T., de Witte, I., Drenth, A., Alfonso, C., and Govers, F. 1997. AFLP linkage map of the oomycete Phytophthora infestans. Fungal Genet. Biol. 21:278-291.

van der Lee, T., Robold, A., Testa, A., van 't Klooster, J. W., and Govers, F. 2001. Mapping of avirulence genes in Phytophthora infestans with amplified fragment length polymorphism markers selected by bulked segregant analysis. Genetics 157:949-956.

van der Vossen, E., Sikkema, A., te Lintel Hekkert, B., Gros, J., Stevens, P., Muskens, M., Wouters, D., Pereira, A., Stiekema, W., and Allefs, S. 2003. An ancient $R$ gene from the wild potato species Solanum bulbocastanum confers broad-spectrum resistance to Phytophthora infestans in cultivated potato and tomato. Plant J. 36:867-882.

van der Vossen, E. A., Gros, J., Sikkema, A., Muskens, M., Wouters, D., Wolters, P., Pereira, A., and Allefs, S. 2005. The Rpi-blb2 gene from Solanum bulbocastanum is an $\mathrm{Mi}-1$ gene homolog conferring broad-spectrum late blight resistance in potato. Plant J. 44:208-222.

van West, P., de Jong, A. J., Judelson, H. S., Emons, A. M. C., and Govers, F. 1998. The ipiO gene of Phytophthora infestans is highly expressed in invading hyphae during infection. Fungal Genet. Biol. 23:126-138.

Vleeshouwers, V. G. A. A., van Dooijeweert, W., Paul Keizer, L. C., Sijpkes, L., Govers, F., and Colon, L. T. 1999. A laboratory assay for Phytophthora infestans resistance in various Solanum species reflects the field situation. Eur. J. Plant Pathol. 105:241-250.

Vleeshouwers, V. G. A. A., Driesprong, J.-D., Kamphuis, L. G., TortoAlalibo, T., Van't Slot, K. A. E., Govers, F., Visser, R. G. F., Jacobsen, E., and Kamoun, S. 2006. Agroinfection-based high-throughput screening reveals specific recognition of INF elicitins in Solanum. Mol. Plant Pathol. 7:499-510.

Wastie, R. L. 1991. Breeding for resistance. Pages 193-224 in: Advances in Plant Pathology, vol. 7. D. S. Ingram and P. H. Williams, eds. Academic Press, London.

Whisson, S. C., van der Lee, T., Bryan, G. J., Waugh, R., Govers, F., and Birch, P. R. 2001. Physical mapping across an avirulence locus of Phytophthora infestans using a highly representative, large-insert bacterial artificial chromosome library. Mol. Genet. Genomics 266:289-295.

Whisson, S. C., Boevink, P. C., Moleleki, L., Avrova, A. O., Morales, J. G., Gilroy, E. M., Armstrong, M. R., Grouffaud, S., van West, P., Chapman, S., Hein, I., Toth, I. K., Pritchard, L., and Birch, P. R. J. 2007. A translocation signal for delivery of oomycete effector proteins into host plant cells. Nature 450:115-118.

\section{AUTHOR-RECOMMENDED INTERNET RESOURCE}

Broad Institute, $P$. infestans database: www.broad.mit.edu/annotation/genome/phytophthora_infestans 